\section{Neutrophilic dermatoses in a patient with collagenous colitis}

\author{
Didac Barco,' Maria A. Barnadas,' \\ Esther Roé, ${ }^{1}$ Francisco J. Sancho, ${ }^{2}$ \\ Elena Ricart, ${ }^{3}$ Agustín Alomar ${ }^{1}$ \\ 'Department of Dermatology, \\ ${ }^{2}$ Department of Pathology, \\ ${ }^{3}$ Department of Digestive Diseases, \\ Hospital de la Santa Creu i Sant Pau, \\ Barcelona, Spain
}

\begin{abstract}
We report the case of a 75-year old woman with collagenous colitis who presented with erythematous and edematous plaques on the periorbital and eyelid regions, accompanied by oral ulcers. Histopathology showed a dermal neutrophilic infiltrate plus mild septal and lobular panniculitis with lymphocytes, neutrophils and eosinophils. Five years earlier she had presented a flare of papules and vesicles on the trunk, together with oral ulcers; a skin biopsy revealed a neutrophilic dermal infiltrate and Sweet's syndrome was diagnosed. Both the neutrophilic panniculitis and the Sweet's syndrome were accompanied by fever, malaise and diarrhea. Cutaneous and intestinal symptoms disappeared with corticoid therapy. The two types of neutrophilic dermatoses that appeared in periods of colitis activity suggest that intestinal and cutaneous manifestations may be related.
\end{abstract}

\section{Introduction}

Collagenous colitis is an inflammatory bowel disease ${ }^{1}$ characterized by normal macroscopic morphology of the colonic mucosa but having a specific histological feature: a collagen band deposition in the lamina propria. Although collagenous colitis has been linked to several neutrophilic dermatoses, ${ }^{3-12}$ we have found no reports in the literature associating the disorder with Sweet's syndrome and/or neutrophilic panniculitis. We describe the case of a woman who developed Sweet's syndrome and a neutrophilic infiltrate, mainly confined to the panniculus, during periods of collagenous colitis activity. Both cutaneous and digestive symptoms responded to steroid therapy.

\section{Case Report}

A 75-year old woman presented with ery- thematous and edematous plaques on the interciliary region in December 2005. Her medical history included a collagenous colitis diagnosed in 1990 from multiple biopsies of the rectum, colon and cecum during the workup for chronic watery diarrhea. Moderate chronic inflammation of the lamina propria and irregular thickening of the basal membrane were observed. The patient did not undergo regular check-ups at our center and chronic diarrhea continued. She took only sporadic loperamide.

She first visited our Dermatology department in April 2002 when she presented oral ulcers and erythematous papules and vesicles on her lower limbs and trunk. She complained of malaise, arthralgias, fever, diarrhea and progressive weight loss in the previous two weeks. A skin punch biopsy showed acute and chronic perivascular, superficial and diffuse dermatitis with numerous polymorphonuclear lymphocytes (Figures 1 and 2). Sweet's syndrome was diagnosed and she was admitted to hospital. She was put on oral prednisone at $1 \mathrm{mg} / \mathrm{kg} /$ day and proctitis symptoms, cutaneous and oral lesions resolved within a week. Prednisone was gradually tapered off $(10 \mathrm{mg}$ every five days) until complete resolution.

In December 2005 she complained of fever, oral ulcers and erythematous plaques on periorbital and eyelid regions of 30 days' duration. A course of $0.5 \mathrm{mg} / \mathrm{kg} /$ day oral prednisone was prescribed and skin lesions improved. When steroids were discontinued, the lesions relapsed and diarrhea and fever reappeared.

The patient returned to our Dermatology unit one month later and clinical examination revealed erythematous, edematous and well-defined plaques around the eyes (Figure 3 ) and oral ulcers (Figure 4). She did not respond to co-amoxiclav $500 \mathrm{mg} / 8 \mathrm{~h}$ and was put on prednisone at $20 \mathrm{mg} /$ day. The cutaneous lesions disappeared and intestinal symptoms improved. Multiple rectum, sigmoid, colon and cecum biopsies were consistent with collagenous colitis.

After several days' treatment, the patient stopped taking the steroids. The periorbital plaques flared up again. A skin punch biopsy detected an inflammatory process, mainly involving the subcutaneous fat. It showed a septal and lobular pattern, and the inflammatory infiltrate was composed of lymphocytes, histiocytes and neutrophils. There was a mild perivascular and interstitial infiltrate with neutrophils and lymphocytes in the reticular dermis. No necrosis was noted (Figures 5 and 6). Prednisone $20 \mathrm{mg} /$ day was reintroduced and the skin lesions healed completely. Treatment was slowly tapered (approximately $5 \mathrm{mg}$ every ten days) and the patient is currently on prednisone at $2.5 \mathrm{mg} /$ day. Intestinal symptoms are under control.
Correspondence: Didac Barco Nebreda, Department of Dermatology, Hospital de la Santa Creu i Sant Pau, c/Sant Antoni Maria Claret, 167 08025 Barcelona, Spain.

E-mail: dbarco@santpau.cat

Key words: neutrophilic dermatoses, Sweet's syndrome, neutrophilic panniculitis, inflammatory bowel disease, collagenous colitis.

Contributions: all authors had full access to all of the data in the study and take responsibility for the integrity of the data and the accuracy of the data analysis. All authors participated in study concept and design. DB, MB, FS and ERi, acquisition of data; $\mathrm{DB}, \mathrm{MB}$ and $\mathrm{ERi}$, analysis and interpretation of data; $\mathrm{DB}, \mathrm{MB}$ and $\mathrm{AA}$, drafting of the manuscript; DB, MB and AA, critical revision of the manuscript for important intellectual content. AA, study supervision.

Conflict of interest: the authors report no conflicts of interest.

Received for publication: 16 September 2009 Revision received: 22 January 2010.

Accepted for publication: 22 January 2010.

This work is licensed under a Creative Commons Attribution 3.0 License (by-nc 3.0).

(C) Copyright D. Barco et al., 2010

Licensee PAGEPress, Italy

Dermatology Reports 2010; 2:e5

doi:10.4081/dr.2010.e5

\section{Discussion}

We consider that the two forms of neutrophilic dermatoses in this patient with collagenous colitis were reactive to colitis flares. The first skin eruption was diagnosed as Sweet's syndrome on the basis of clinical and histological presentation. The second dermatosis was a neutrophilic panniculitis. There was a temporal correlation between cutaneous and digestive symptoms since all skin eruptions were accompanied by diarrhea and all intestinal biopsies performed during these periods were consistent with collagenous colitis.

Two types of subcutis involvement have been described in patients with Sweet's syndrome. The most common pattern is a septal panniculitis, similar to that seen in erythema nodosum. ${ }^{5}$ It may appear as an isolated event or simultaneously with a classical Sweet's syndrome. ${ }^{5,11,12}$ The second type is a pure lobular neutrophilic infiltration of subcutaneous fat (neutrophilic panniculitis). ${ }^{5,13}$ Several reports have been published regarding neutrophilic dermatoses presenting as facial or periorbital edematous plaques, sometimes simulating facial cellulitis. ${ }^{14}$

We know of only three reports of cutaneous manifestations associated to collagenous coli- 


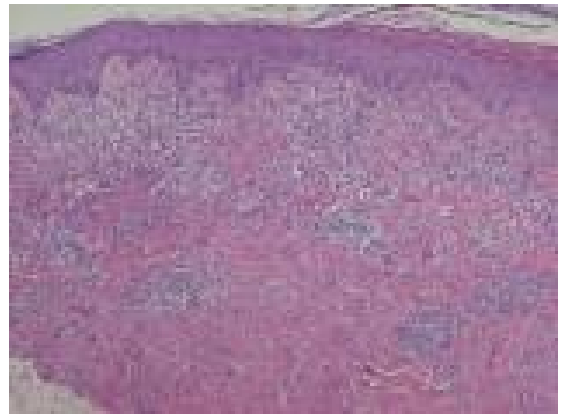

Figure 1. Histopathological study of skin biopsy showing a perivascular and interstitial inflammatory infiltrate composed by lymphocytes, histiocytes and abundant neutrophils (HEx100).

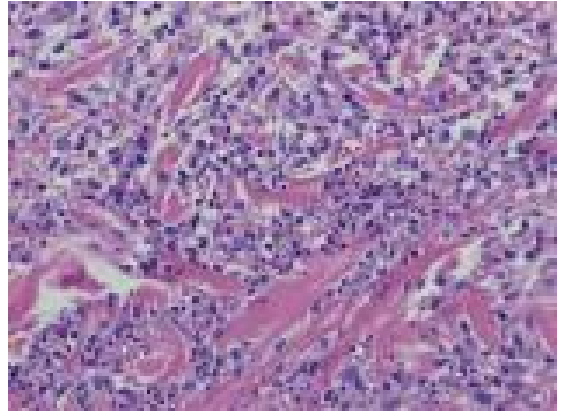

Figure 2. Detail of the lesion, showing dense neutrophilic infiltrate (HEx400).
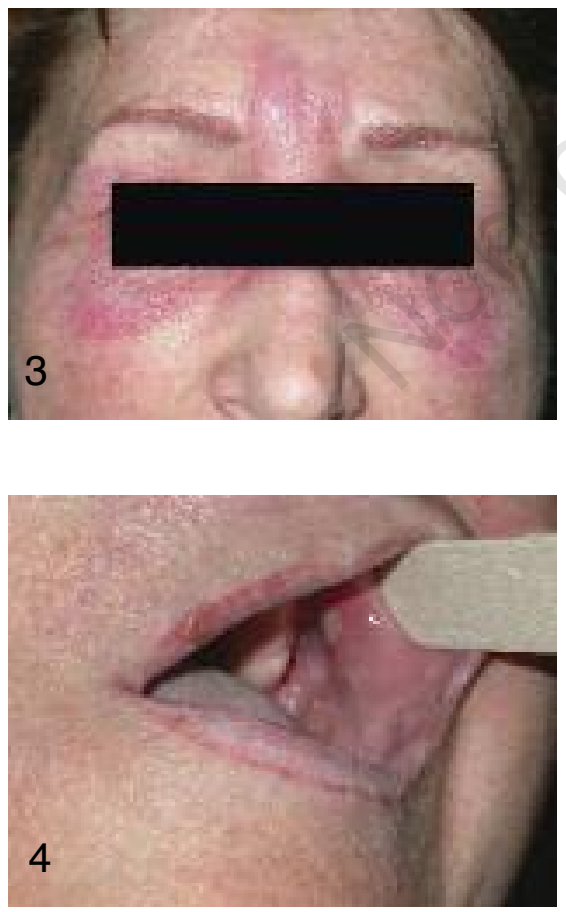

Figures 3 and 4. Clinical aspect of the facial and oral lesions.
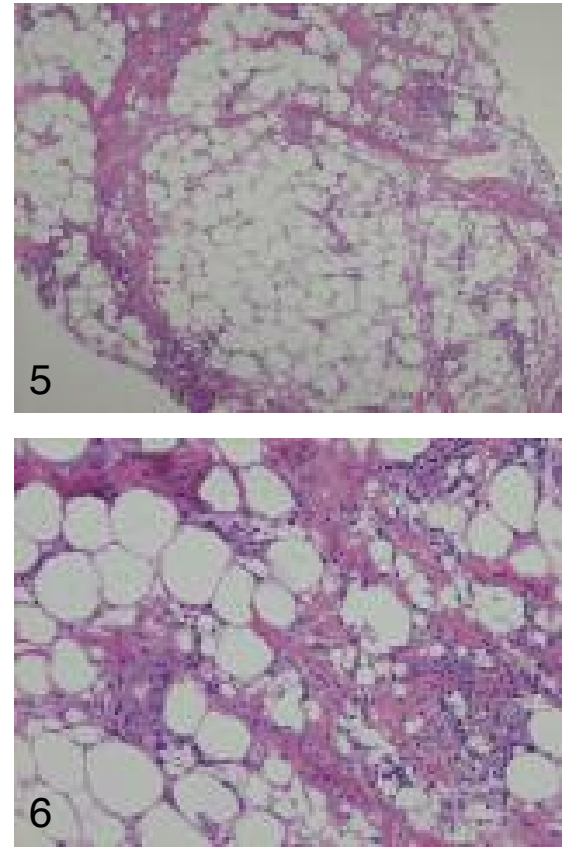

Figures 5 and 6. Histopathological study of skin lesion showing a neutrophilic infiltrate in the subcutaneous fat between septa and adipocytes (HEx100, HEx400).

tis, and all three corresponded to pyoderma gangrenosum (one was a peristomal lesion). ${ }^{15}$ ${ }^{17}$ To the best of our knowledge, this is the first case of collagenous colitis associated to Sweet's syndrome and neutrophilic panniculitis. Most cutaneous manifestations of inflammatory bowel diseases lie within the spectrum of neutrophilic dermatoses: erythema nodosum, pyoderma gangrenosum, Sweet's syndrome and neutrophilic pustulosis. There are several reports in the literature of inflammatory bowel disease patients who developed reactive lesions (erythema nodosum, pyoderma gangrenosum, generalized pustulosis) together with Sweet's syndrome as in our case, but these did not occur simultaneously., ${ }^{3,11,12,18}$

When associated to inflammatory bowel disease, Sweet's syndrome may be a marker of its activity, as it can run parallel to its clinical course. ${ }^{4,6,7,9,11,19-20}$ and relapse during bouts of inflammatory bowel disease. ${ }^{6,11}$ Sweet's syndrome is considered to be an inflammatory bowel disease-associated dermatosis..$^{3,4,6-12,18-20}$ It is important to note that the association between Sweet's syndrome and inflammatory bowel diseases encompasses special features. In this context, the eruption shows a strong predilection for women, and all the reports of inflammatory bowel diseases associated to Sweet's syndrome have colonic or perianal involvement. . $3,7,8,10,19,20$ Findings in our patient support these data.

In conclusion, in view of the parallel course with the intestinal disease, the response to steroids, and the reports in the literature relat- ing inflammatory bowel diseases with neutrophilic dermatoses, we consider that both the Sweet's syndrome and the neutrophilic panniculitis in the present patient were related to collagenous colitis. These findings suggest that collagenous colitis could be added to the list of inflammatory bowel diseases associated to neutrophilic dermatoses.

\section{References}

1. Schiller LR. Diagnosis and management of microscopic colitis syndrome. J Clin Gastroenterol 2004;38: S27-30.

2. Tremaine W. Collagenous colitis and lymphocytic colitis. J Clin Gastroenterol 2000; 30:245-9.

3. Mendoza JL, Garcia-Paredes J, Pena AS, et al. Continuous spectrum of neutrophilic dermatoses in Crohn's disease. Rev Esp Enferm Dig 003;95:229-32.

4. Anglada Pintado JC, Michan Dona A, Silva Abad A, et al. Sweet's syndrome and intestinal inflammatory disease. A case report and review of the literature. An Med Interna 2002;19:8;419-22.

5. Sutra-Loubet C, Carlotti A, Guillemette J, Wallach D. Neutrophilic panniculitis. J Am Acad Dermatol 2004;50:280-5.

6. Actis GC, Lagget M, Ciancio A, et al. Recurrent Sweet's syndrome in reactivated Crohn's disease. J Clin Gastroenterol. 1995;21:317-9.

7. Vaz A, Kramer K, Kalish RA. Sweet's syndrome in association with Crohn's disease. Postgrad Med J 2000;76:713-4.

8. Ytting H, Vind I, Bang D, Munkholm P. Sweet's syndrome - An extraintestinal manifestation in inflammatory bowel disease. Digestion 2005;72:195-200.

9. Burrows NP. Sweet's syndrome in association with Crohn's disease. Clin Exp Dermatol 1995;20:279-80.

10. Rappaport A, Shaked M, Landau M, Dolev E. Sweet's syndrome in association with Crohn's disease: report of a case and review of the literature. Dis Colon Rectum. 2001;44:1526-9.

11. Sitjas D, Puig L, Cuatrecasas M, De Moragas JM. Acute febrile neutrophilic dermatosis (Sweet's syndrome). Int $\mathbf{J}$ Dermatol 1993;32:261-8.

12. Waltz KM, Long D, Marks JG Jr, Billingsley EM. Sweet's syndrome and erythema nodosum: the simultaneous occurrence of 2 reactive dermatoses. Arch Dermatol 1999;135:62-6.

13. Cooper PH, Frierson HF, Greer KE. Subcutaneous neutrophilic infiltrates in acute febrile neutrophilic dermatosis. Arch Dermatol 1983;119:610-1. 
14. Crum NF, Higginbottom PA, Fehl FC, Graham BS. Sweet's syndrome masquerading as facial cellulitis. Cutis. 2003;71:469-72.

15. Batra AK, Levey JM, Trister J, Patwardhan R. Pyoderma gangrenosum in a patient with collagenous colitis. J Am Acad Dermatol 2003;49:S277-9.

16. Roé E, Dalmau J, Garcia-Navarro X, et al. A case of vulvar pyoderma gangrenosum associated with collagenous colitis. Dermatology. 2006;213:234-5.

17. Davis MD, Nakamura KJ. Peristomal pyoderma gangrenosum associated with collagenous colitis. Arch Dermatol 2007;143: 669-70.

18. Gonzálvez Perales JL, Tamarit Orti R, Ballester Fayos J, et al. A case of Sweet's syndrome associated with Crohn's disease. Gastroenterol Hepatol 1997;20:134-7.
19. Ly S, Beylot-Barry M, Beyssac R, et al. Sweet syndrome associated with Crohn disease. Rev Med Interne 1995;16:931-3.

20. Paoluzi OA, Crispino P, Amantea A, et al. Diffuse febrile dermatosis in a patient with active ulcerative colitis under treatment with steroids and azathioprine: a case of Sweet's syndrome. Case report and review of literature. Dig Liver Dis 2004;36: $361-6$. 